\title{
Vessel traffic disrupts the foraging behavior of southern resident killer whales Orcinus orca
}

\author{
David Lusseau ${ }^{1, *, * *}$, David E. Bain ${ }^{2, * *}$, Rob Williams ${ }^{3,5}$, Jodi C. Smith ${ }^{4}$ \\ ${ }^{1}$ University of Aberdeen, Institute of Biological and Environmental Sciences, Tillydrone Ave, Aberdeen AB24 2TZ, UK \\ ${ }^{2}$ University of Washington, Friday Harbor Laboratories, 620 University Road, Friday Harbor, Washington 98250, USA \\ ${ }^{3}$ Sea Mammal Research Unit, Gatty Marine Laboratory, St Andrews University, St Andrews, Fife KY16 8LB, UK \\ ${ }^{4}$ Coastal-Marine Research Group, Institute of Natural Resources, Massey University at Albany, Private Bag 102904 , \\ North Shore MSC, New Zealand
}

${ }^{5}$ Present address: Marine Mammal Research Unit, University of British Columbia, 2202 Main Mall, Vancouver, British Columbia V6T 1Z4, Canada

\begin{abstract}
Vessel traffic may have contributed to southern resident killer whales Orcinus orca becoming endangered. To determine the importance of this threat, we measured the behavior of southern residents in the presence and absence of vessels from 2003 to 2005 at 2 different sites along San Juan Island, Washington, USA. We observed activity states of killer whale schools using scan sampling and collected information on the number of vessels present at various distances from those. We use first-order, time-discrete Markov chains to estimate state-transition probability matrices under varying boat exposure conditions. Transition probabilities between activity states were significantly affected by vessel traffic. In addition, there was a reduction in time spent foraging, as estimated from the stationary state budget from the Markov chains, confirming an effect also previously observed in northern resident killer whales. If reduced foraging effort results in reduced prey capture, this would result in decreased energy acquisition. Each school was within $400 \mathrm{~m}$ of a vessel most of the time during daylight hours from May through September. The high proportion of time southern resident killer whales spend in proximity to vessels raises the possibility that the short-term behavioral changes reported here can lead to biologically significant consequences.
\end{abstract}

KEY WORDS: Whale watching $\cdot$ Killer whale $\cdot$ Disturbance $\cdot$ Behavioral disruption · Foraging Resale or republication not permitted without written consent of the publisher

\section{INTRODUCTION}

The eastern North Pacific southern resident stock of killer whales Orcinus orca declined to fewer than 80 individuals in 2001, resulting in their listing as 'depleted' under the Marine Mammal Protection Act and 'endangered' under the United States and Washington State Endangered Species Acts, and Canada's Species at Risk Act. The causes of this decline are uncertain, but many scientists consider a combination of reduction in prey resources, toxic chemicals, disturbance from vessel traffic, and other factors to have contributed (Krahn et al. 2004, Wiles 2004, Killer Whale Recovery Team 2005).

*Email: d.lusseau@abdn.ac.uk,

** These authors contributed equally to this article and can be considered joint first authors
Krahn et al. (2004) noted that the southern resident killer whale population increased at an normal rate in the late 1980s $\left(\sim 3 \% \mathrm{yr}^{-1}\right)$. Growth began to slow in the early 1990s and was followed by a decline of $20 \%$ from 1996 to 2001. This stock is composed of 3 social units (pods). $\mathrm{J}$ and $\mathrm{K}$ pods exhibited little change in number during this period, in contrast to the expected growth. In contrast, the L pod not only failed to grow, but it declined, and this decline resulted in the decline in number of the entire population. Factors in the inshore waters of Washington and British Columbia, such as declines in prey abundance, toxins, and vessel traffic may be responsible for the lack of growth in all 3 pods. Differences in usage patterns of the inshore waters

(C) Inter-Research $2009 \cdot$ www.int-res.com 
among the different pods (Bigg et al. 1990, Olesiuk et al. 1990, Osborne 1999, Hauser et al. 2006) may account for some of the additional decline experienced by the L pod alone, but factors external to these waters are likely to be of similar importance to factors in inshore waters (regional differences in prey abundance [Protected Resources Division 2004], perhaps entanglement, and exposure to oil, among others).

Vessel traffic may have contributed to the decline through a variety of mechanisms. Collisions between vessels and killer whales occur occasionally in residents, including southern residents, and other killer whales and result in injury or death (Ford et al. 2000, G. M. Ellis pers. comm.). Unburned fuel and exhaust from vessels may contribute to toxin load. The presence of noise from vessels may contribute to stress (Romano et al. 2004). Noise from vessel traffic may mask echolocation signals (Bain \& Dahlheim 1994, Erbe 2002), reducing foraging efficiency. Behavioral responses may result in increased energy expenditure, or disrupt feeding activity, which may reduce energy acquisition (Bain 2002, Williams et al. 2006). Energetic mechanisms for impact are of particular concern, since southern resident killer whales may be food limited.

Repeated disturbance of wild animals is implicated as a factor reducing the quality of life, foraging efficiency, fitness, or reproductive success of individual animals. Studies link anthropogenic disturbance to changes in foraging behavior (e.g. Galicia \& Baldassare 1997), reproductive success (e.g. Safina \& Burger 1983), and mating system and social structure (e.g. Lacy \& Martins 2003). These, in turn, either singly or synergistically, can influence population dynamics and viability (Lusseau et al. 2006). Effects of vessel traffic have been studied in a range of cetacean species. Effects vary within and between species, and included changes in respiration patterns, surface active behaviors, swimming velocity, vocal behavior, activity state, inter-individual spacing, wake riding, approach and avoidance, and displacement from habitat. Williams et al. (2006) found northern residents were less likely to forage in the presence vessels. Vessel traffic can also displace bottlenose dolphins (Lusseau 2005, Bejder et al. 2006) and significantly alter their behavioral budget (Lusseau 2004).

In the San Juan and Gulf Islands region, the commercial whale-watching day runs from about 09:00 to 21:00 h in summer, and until sunset in spring and early fall. In addition to commercial whale-watching vessels, other vessels are also in contact with whales throughout the day. These include recreational and research vessels, cruise ships, sport and professional fishing vessels, and intermittently commercial freight ships. Due to the variety of vessels observed in the presence of whales, the term whale watching as used in the pre- sent paper refers to all whale-oriented vessel traffic, regardless of whether the vessels are commercial whale-watching vessels or not. Because these whales are in the presence of vessels during much of the day, the potential for cumulative effects makes it important to investigate whether the behavior of killer whales is altered in the presence of vessels.

Assessing variation in behavior under different conditions is difficult, due to the inherent temporal dynamics of activity states, as they tend to occur in bouts. We used Markov chains to quantify this temporal dependence and assess how exposure conditions changed it (Cane 1959, Lusseau 2003). The same temporal biases inherent to behavioral data mean that simple tallies of state samples observed under different boat conditions will not represent the true behavioral budget of the population under these exposure conditions (Guttorp 1995, Lusseau 2003). However, we can infer these budgets from the stationary behavior of the Markov chains developed for each exposure condition.

Here, we assess whether boat traffic affects the behavioral dynamics and behavioral budget of this population of killer whales. Given the importance of food limitation on the dynamics of this population, we particularly determined whether they disrupt foraging activities and the range of influence of vessels (the maximum distance between whales and boats eliciting disruptions).

\section{MATERIALS AND METHODS}

Study areas. From 28 July to 30 September 2003, 1 May to 31 August 2004, and 15 May to 31 July 2005, a land-based team of observers monitored behavior of whales and activity of boats from 2 study sites on the west coast of San Juan Island, WA, USA. One site (hereafter referred to as the north site) was located at $48^{\circ} 30.561^{\prime} \mathrm{N}, 123^{\circ} 8.494^{\prime} \mathrm{W}$ (near Lime Kiln State Park) at an altitude of approximately $99 \mathrm{~m}$ above mean lower low water. The south site was located on Mt. Finlayson $\left(48^{\circ} 27.421^{\prime} \mathrm{N}, 122^{\circ} 59.401^{\prime} \mathrm{W}\right)$ at a height of $72 \mathrm{~m}$, and the view of the eastern portion of Juan de Fuca Strait was unobstructed. Whales have been reported to use this area heavily for foraging, whereas the north site appeared to be used primarily for travel and socializing (Heimlich-Boran 1988, Felleman et al. 1991, Hoelzel 1993). Together, these sites were chosen to maximize sample size and to allow the behavioral observations to include the entire repertoire of the population.

Behavioral sampling. During the study periods, $238 \mathrm{~d}$ were spent on effort, of which $128 \mathrm{~d}$ were spent with whales. During that time scan sampling was conducted at 15 min intervals to characterize subgroup size (ranging from 1, to the size of the school in the 
study area), activity state, and the number of vessels within 100,400, and $1000 \mathrm{~m}$ of whales. The activity state subcategories ( 1 to 8 ; Table 1 ) were combined to match the categories described by Ford et al. (2000). The resulting activity states were cumulatively inclusive and mutually exclusive. A scanned group was defined as animals within 10 body lengths of one another at the time of a scan-sample observation, using a chain rule (Connor et al. 2000). The identity of group members was recorded, but when individuals were too far away to be identified, their identity was assigned to categories based on size (e.g. calf, juvenile, mediumsized whales [large juveniles or adult females], subadult male, adult male). Sequential observation of focal groups allowed estimating the probability of animals' switching from one activity state to another as a function of vessel traffic.

Vessel traffic sampling. Vessels were counted separately depending on whether or not they were engaged in whale watching, although commercial and recreational whale-watching boats were not distinguished in scan-sample counts. Distances were visually estimated, and, in most instances, the distances were confirmed using coordinates of whales and boats taken using a theodolite. These theodolite-based Quality Assurance and Control (QA/QC) measurements were made continuously throughout the study to insure observer reliability and consistency (Williams et al. 2009). Observer errors never exceeded 10\%. Since our analyses are not based on the exact distance between boats and whales, but on the number of boats present within 100,400 , and $1000 \mathrm{~m}$ of the whales, such errors where adequate.
Analyzing scan-sampling data from focal groups. Understanding the recurrence of activity states allows one to understand the likelihood that a state will be disrupted by, in our case, boat presence. The data were a series of scan samples of a focal group that were treated as samples of activity-state sequences. A sequence stopped when sampling stopped on a given day or when a focal group ceased to exist due to changes in group membership (through fission or fusion with other individuals), or because they left the study area. For the purposes of the present study, we were only interested in understanding the change in the likelihood that when a group was in State A they would be in State B 15 min later (i.e. at the next scan). These are called firstorder transitions in activity. This sequence of discrete time samples could be treated as a Markov chain (Lusseau 2003, 2004) because it was ergodic. A time series is ergodic when transitions between all states are possible; in the present study a group could be involved in a transition from any state to another (there was no biological constraint preventing whales from switching between one state and the others). We then assessed whether our first-order assumption was warranted. That is, we assessed whether the assumption that a state was only dependent on the immediately preceding sample best explained sequences by comparing the Bayes information criterion (BIC) for first-order chains to BIC for zero-order chains and second-order chains (Guttorp 1995, Lusseau 2003). BIC provides a consistent estimate of the order of a Markov chain. The higher the $\mathrm{BIC}$, the more information the order provides on the sequences. A BIC difference of 9.2 is sufficient to determine the best-fitting order (Guttorp 1995).

Table 1. Orcinus orca. Definition of activity states used in the present study

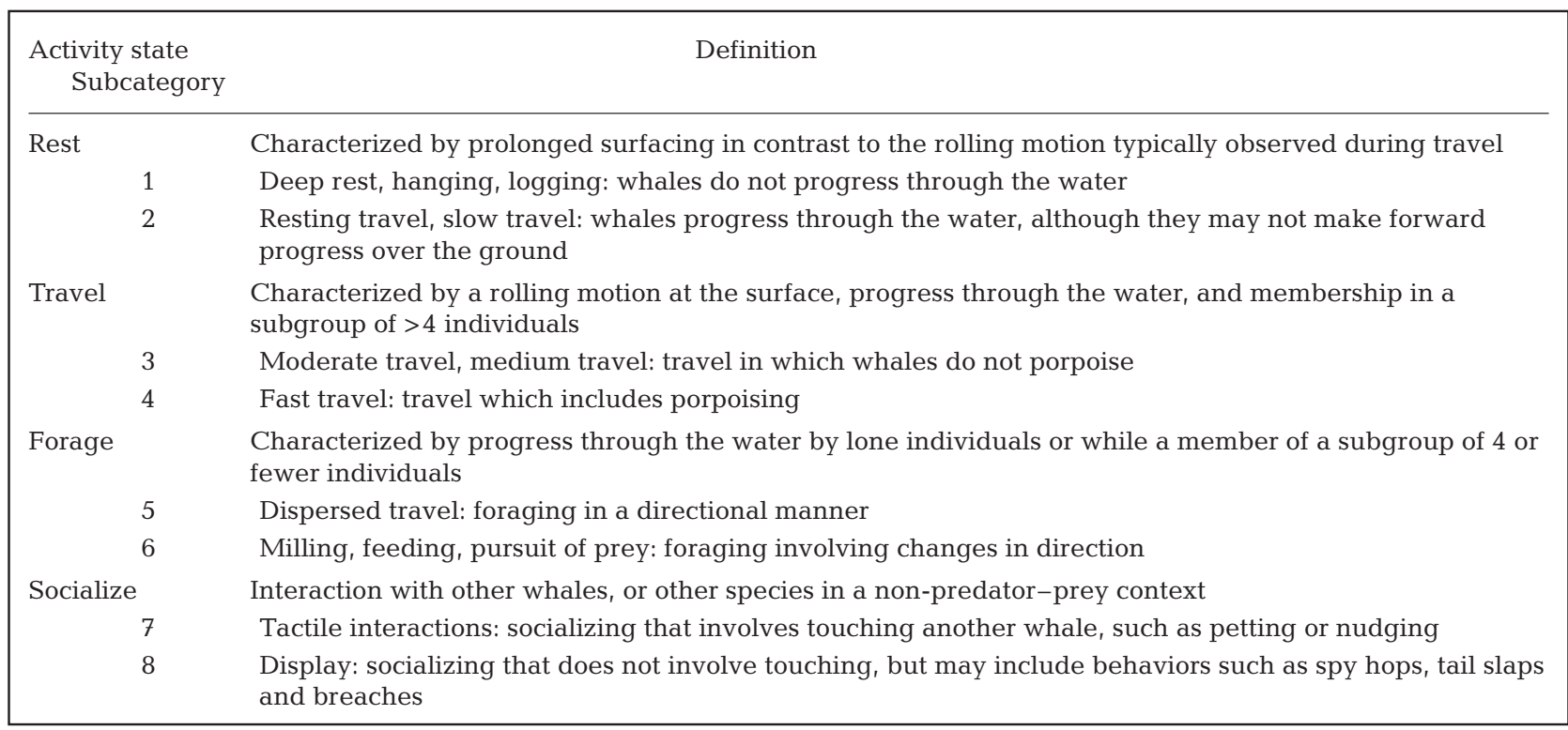


To understand the effect of boat interactions on the state transitions, the number of vessels in the field of view was counted, as these vessels may have contributed to ambient noise in the area (Bain pers. obs.). The number of vessels within 100,400, and $1000 \mathrm{~m}$ of subgroups were also counted. The numbers within specific distances were used as candidate explanatory covariates, to assess whether the probability of animals switching among activity states varied as a function of boat traffic. We therefore constructed a transition matrix, representing the probabilities for whales to be observed in state $i$ at time $t$ and subsequently in state $j$ at the next sampling event $(t+15 \mathrm{~min})$ :

$$
\mathrm{p}_{i j}=\frac{\mathrm{e}_{i j}}{\sum_{k} \mathrm{e}_{i k}}
$$

where $e_{i j}$ is the total number of times the transition was observed and $\sum_{k} \mathrm{e}_{i k}$ is the total number of time state $i$ was observed as the starting state.

Analyzing the influence of vessel traffic and other factors on behavior. We were able to explore the effects of several parameters on the likelihood to go from one state to another by comparing the behavioral contingency tables (preceding to succeeding states) obtained for different levels of different factors (Lusseau 2003). Using these multidimensional contingency tables, we used general log-linear analyses (SPSS algorithm), to test whether site (north/south), year (2003/2004/2005), pod (J, K, and L), or vessel traffic (boat present/absent within 100, 400, and $1000 \mathrm{~m}$ ) affected transitions in activity states, which was the likelihood that focal groups went from a preceding behavior (state at time $t$ ) to a succeeding behavior (state at time $t+15 \mathrm{~min}$ ). Log-linear analyses can be thought of as generalized linear models for categorical data (with a Poisson distribution and log link). This technique is described in more detail by Lusseau (2003, 2004). The response variable in these analyses was the succeeding behavior $(S)$, and we estimated whether the observed count of succeeding behavior was influenced by the preceding behavior $(P)$, the year $(Y)$, boat presence $(B)$, and/or location $(L)$. Given that we estimated the behavioral sequences using firstorder Markov chains, we were assuming that the interaction $P S$ was significant. Given that sampling was based on observational data, we could not control sample size for each factor, and therefore the count of preceding behavior was influenced by other factors (Caswell 2001). The log-linear analysis fits a saturated model to the dataset, i.e. a model that considers all interactions, indicated by BLYPS in the first analysis. The effects of the different factors can be tested by comparing different fitted models using likelihood ratio tests. Here, the null hypothesis is that succeeding behaviors are independent of boat presence, year, and location, given preceding behaviors. This null hypothesis corresponds to the null model $P S+L B Y P$. The influence of factors was assessed in 2 manners. First, we estimated the Akaike information criterion (AIC) for each model, and the best fitting model minimized AIC. Secondly, we assessed whether the presence of a factor in the log-linear model added a significant contribution to explaining the data's variance using likelihood ratio tests. For example, the effect of boat presence in the first analysis can be evaluated by comparing the null model and $B P S+L B Y P$ because adding the terms $B S$ and $B P S$, which correspond to a boat presence effect on the observed count of succeeding behaviors, to the null model results in the model $B P S+L B Y P$. The significance of the boat presence effect can then be tested by comparing the goodnessof-fit of both models. The difference in goodness-offit $\left(\triangle G^{2}=G_{B P S, L B Y P}^{2}-G^{2}{ }_{P S, L B Y P}\right)$ is the likelihood ratio testing the significance of the addition of terms $B S$ and $B P S$ with degrees of freedom equal to the difference in the degrees of freedom for the 2 models. The effect of the various factors can be tested at various stages by adding the effect to different models that already consider other factors (Fig. 1). We tested the interactions between year, site, and boat presence and their influences on behavioral transitions.

Influence of pod identity. We then tested whether the pod identity of the focal whales influenced the previous analysis. For this analysis we only retained focal schools that were composed exclusively of members of 1 pod. Due to sample size constraints the latter analysis was carried out on only 2 behavioral states (foraging or not foraging), while the former was carried out on all states.

Influence of distance between boats and whales. To assess whether distance to boats influenced the behavior of killer whales, we calculated the likelihood that whales that were foraging stayed foraging when boats interacted with them at distances of 100,400, and $1000 \mathrm{~m}$. We also looked at the effect of boat presence on the likelihood that whales that were foraging would stay foraging by comparing control situations (no boats within the given distance band) to impact ones. In all these analyses, foraging was selected because recent studies show that northern resident killer whales were more likely to switch activity states when boats approached foraging whales than when whales were engaged in other activity states. Furthermore, alteration to this state is likely to carry larger energetic consequences for killer whales, because it has the potential not only to increase energetic expenditure, but also to reduce acquisition (Williams et al. 2006).

We analyzed the scans containing distances between vessels and groups to determine mean and maximum 


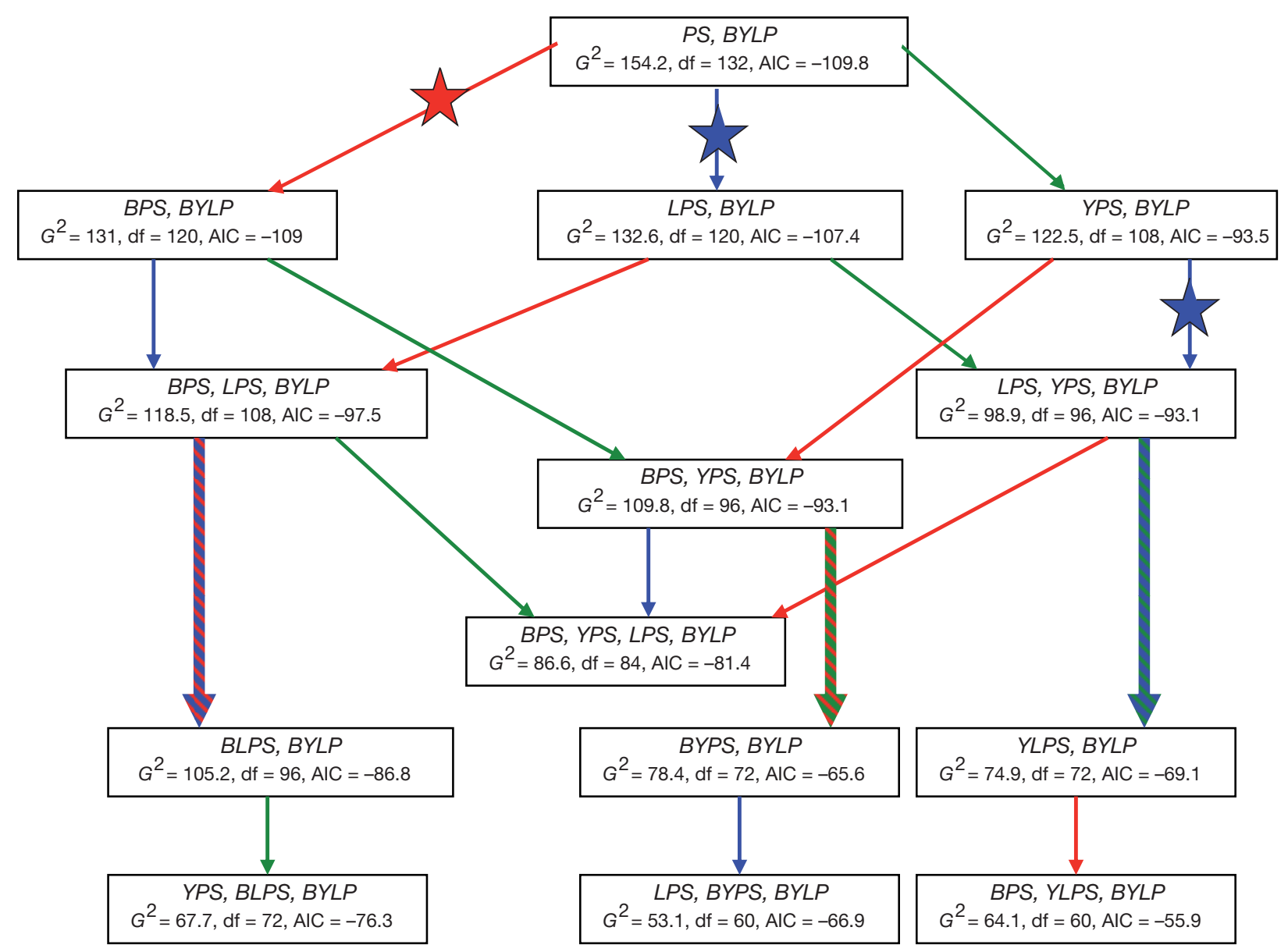

Fig. 1. Tests of boat presence within $100 \mathrm{~m}(B)$, site ( $L$ for location to avoid confusion in abbreviations), and year of sampling $(Y)$ effects on behavior transitions ( $P S$ ) using log-linear analyses. Models and their respective goodness-of-fit $G^{2}$ statistics, degrees of freedom, and Akaike information criterion (AIC) values are shown in the boxes (adapted from Caswell 2001). Terms added are color coded. Blue arrows represent the addition of a site effect ( $L S, L P S$ terms added to the previous model), red arrows represent the addition of a boat effect $(B S, B P S)$, and green arrows represent the addition of a year effect (YS, YPS). To those terms correspond an increment in $G^{2}$ and degrees of freedom, which are used to test for the significance of the term addition. Arrows are marked with a star when the term addition is significant $(p<0.05)$. The top left star indicates a significant boat effect; the center and right stars indicate significant site effects. Year effects were non-significant

vessel counts along with the proportion of time groups spent within 100, 400, or $1000 \mathrm{~m}$ of the nearest vessel (e.g. proportion of time within $100 \mathrm{~m}$ equals the number of scans with boats within $100 \mathrm{~m}$ divided by the number of scans in which vessel distances were recorded).

Behavioral budget variations. Finally, we assessed variation in behavioral budget under different conditions. We estimated budgets using the long-term behavior of the transition matrices. Transition matrices are based on ergodic time series, which means that eigenanalysis of this matrix reveals several properties of activity states. Applying the Perron-Frobenius theorem we show that the transition matrix of long-term behavior, i.e. the amount of time that the whales spent in each activity state, can be approximated by the left eigenvector of the dominant eigenvalue of the matrix (Lusseau 2003). Ultimately, this approach can be used to calculate stable, unbiased activity budgets in contrast with budgets obtained from sample tallies that can be influenced by autocorrelation issues. Further, reliance on transitions rather than individual scans helped control for possible effects of whale behavior on vessel behavior.

\section{RESULTS}

Over the 3 field seasons we observed 593 behavioral transitions in Orcinus orca (135 in 2003, 217 in 2004, and 251 in 2005 out of 373, 1058, and 770 scans, respectively; Table 2). The first-order Markov chain was deemed the 
Table 2. Orcinus orca. Number of activity state transitions observed in the presence/absence of boats within $100 \mathrm{~m}$

\begin{tabular}{|ccccccc|}
\hline \multirow{2}{*}{ Site } & \multicolumn{2}{c}{2003} & \multicolumn{2}{c}{2004} & \multicolumn{2}{c|}{2005} \\
& No boat & Boat & No boat & Boat & No boat & Boat \\
\hline North & 49 & 30 & 121 & 30 & 111 & 52 \\
South & 45 & 11 & 46 & 20 & 40 & 48 \\
\hline
\end{tabular}

more appropriate way to estimate the behavioral sequences because it provided more information than zero-order or second-order Markov chains $\left(\mathrm{BIC}_{0 \text {-order }}=\right.$ $\left.-357.5, \mathrm{BIC}_{1 \text {-order }}=-262.8, \mathrm{BIC}_{2 \text {-order }}=-293.8\right)$. We assessed the effects of year (2003/2004/2005), site (north/south), and vessel traffic (no boat within $100 \mathrm{~m}$, boat present within $100 \mathrm{~m}$ ) on first-order behavioral transitions using a 5-way, log-linear analysis (LLA). Due to small sample size the full interaction of the 3 independent variables could not be quantified (Table 2). This analysis reveals that 3 models provided more information on the data's variance (Fig. 1). The null model, i.e. no effects from independent variables $(P S, B Y L P)$, the model considering a site effect ( $L P S, B Y L P)$, and the model considering a boat effect $(B P S, B Y L P)$, all had lower AIC values than the other models (Table 3 ), indicating that each of the null, site effect, and boat effect models were plausible. In addition, adding a boat and site effect to the model provided significantly more explanation of the data variance (significant effects repre-

Table 3. Information theoretic approach used to select models, from Fig. 1, providing the most parsimonious explanation for the variation in the scan-sample dataset. The selection is based on the Akaike information criterion (AIC). The models are described in Fig. 1. The difference between the best fitting model and the other models, $\triangle \mathrm{AIC}$, helps in defining models that are less plausible (usually $\triangle \mathrm{AIC}>4$ to 8 ). The likelihood of the model given the data can be approximated using an exponential transformation of $\triangle \mathrm{AIC}$ : $\ell\left(\right.$ model $\mathrm{i}_{\mathrm{i}} \mid$ data $)=\mathrm{e}^{\left(-0.5 \Delta \mathrm{AIC}_{\mathrm{i}}\right)}$. The weight of evidence provided by each model can be obtained by normalizing these likelihoods so that they sum to 1

\begin{tabular}{|lrcc|}
\hline Model & AIC & $\Delta$ AIC & Weight \\
\hline Null model & -109.8 & 0 & 0.507 \\
Boat & -109.0 & 0.8 & 0.340 \\
Site & -107.4 & 2.4 & 0.153 \\
Year & -93.5 & 16.3 & 0.0001 \\
Boat + Site & -97.5 & 12.3 & 0.001 \\
Site + Year & -93.1 & 16.7 & $<0.0001$ \\
Boat + Year & -82.2 & 27.6 & $<0.0001$ \\
Boat + Year + Site & -81.4 & 28.4 & $<0.0001$ \\
Boat $\times$ Site & -86.8 & 23.0 & $<0.0001$ \\
Boat $\times$ Year & -65.6 & 44.2 & $<0.0001$ \\
Year $\times$ Site & -69.1 & 40.7 & $<0.0001$ \\
Year + (Boat $\times$ Site $)$ & -76.3 & 33.5 & $<0.0001$ \\
Site + (Boat $\times$ Year) & -66.9 & 42.9 & $<0.0001$ \\
Boat $+($ Year $\times$ Site $)$ & -55.9 & 53.9 & $<0.0001$ \\
\hline
\end{tabular}

sented by stars on Fig. 1, see also Table 3), the site effect still being significant after the year effect has been taken into consideration. Significance of the terms were derived from the likelihood ratio tests as described in 'Materials and methods'. From this analysis, we can conclude both that boat presence within $100 \mathrm{~m}$ of the focal whales affected their behavioral transitions and that the whales behaved differently at the 2 sites, in contrast to the null model that was not rejected when considering the AIC value alone. The introduction of a boat effect explains significantly more variation in the dataset than the null model alone (as shown by the red star in Fig. 1). We can therefore conclude that while intrinsic behavioral processes and data structure (the null model) as well as site explain some of the variation in the dataset, a boat effect cannot be excluded (because of the AIC weights) and should be included as well (because this parameter provides significantly more information than the null model alone).

\section{Influence of pod identity}

The southern resident community of killer whales is composed of 3 pods (, $\mathrm{K}$, and L), which do not spend the same amount of time within Puget Sound (Olesiuk et al. 1990, Ford et al. 2000). This may result in differences in the cumulative exposure of each pod to whale watching and therefore may lead to variation in the way these pods respond to boat presence. We therefore assessed whether the identity of the focal whales affected the behavioral response observed in relation with boat presence. To do so, we conducted a log-linear analysis including pod identity and boat presence within $100 \mathrm{~m}$ as independent variables (Table 4). The log-linear analysis showed that there does not appear to be any variation in the way that whales responded to boat presence depending on their pod, because there was no interaction between the pod and boat effect (Table 5). The analysis shows that while the best model was the null model, both pod effect and boat effect could not be discounted ( $\triangle \mathrm{AIC}<2$; Table 5$)$. This highlights that potentially the site effect we observed in the previous analysis (Fig. 1) may just be a reflection of the

Table 4. Orcinus orca. Number of activity state transitions observed with and without boats present within $100 \mathrm{~m}$ of subgroups for each pod for both sites in all years (considering only schools composed solely of members of 1 pod)

\begin{tabular}{|lcc|}
\hline Pod & No boat present & Boat present \\
\hline $\mathrm{J}$ & 158 & 35 \\
$\mathrm{~K}$ & 21 & 21 \\
$\mathrm{~L}$ & 99 & 47 \\
\hline
\end{tabular}


Table 5. Information theoretic approach used to select models, from the log-linear analysis considering pod identity, site, and boat presence, providing the most parsimonious explanation for the variation in the scan-sample dataset. The difference between the best fitting model and the other models, $\triangle \mathrm{AIC}$, helps in defining models that are less plausible (usually $\Delta \mathrm{AIC}>4$ to 8). The likelihood of the model given the data can be approximated using an exponential transformation of $\Delta$ AIC: $\ell\left(\right.$ model $_{\mathrm{i}} \mid$ data $)=\mathrm{e}^{\left(-0.5 \Delta \mathrm{AIC}_{\mathrm{i}}\right)}$. The weight of evidence provided by each model can be obtained by normalizing these likelihoods so that they sum to 1 . mle: maximum likelihood estimate

\begin{tabular}{|lccccc|}
\hline Model & mle & df & AIC & $\Delta$ AIC & Weight \\
\hline Null & 21.43 & 22 & -22.57 & 0 & 0.378 \\
Pod & 14.43 & 18 & -21.57 & 1 & 0.229 \\
Boat & 19.22 & 20 & -20.78 & 1.79 & 0.154 \\
Site & 20.97 & 20 & -19.03 & 3.54 & 0.064 \\
Boat + Site & 18.89 & 18 & -17.11 & 5.46 & 0.025 \\
Boat + Pod & 13.42 & 16 & -18.58 & 3.99 & 0.051 \\
Site + Pod & 12.44 & 16 & -19.56 & 3.01 & 0.084 \\
Site $\times$ Pod & 8.66 & 12 & -15.34 & 7.23 & 0.010 \\
Site $\times$ Boat & 18.21 & 16 & -13.79 & 8.78 & 0.005 \\
Boat $\times$ Pod & 48.79 & 12 & 24.79 & 47.36 & $<0.0001$ \\
Boat $\times$ Pod $\times$ Site & 0 & 0 & 0 & 22.57 & $<0.001$ \\
\hline
\end{tabular}

difference in use of the 2 sites by the 3 pods (Figs. 2 \& 3). J pod seemed to be the pod most likely to be foraging, and, interestingly, they seemed to be more likely to be foraging at the south site, while $\mathrm{K}$ and $\mathrm{L}$ were equally likely to forage at both sites (Fig. 3).

\section{Influence of distance between focal school and boats}

While an effect of boat presence was apparent when boats were within $100 \mathrm{~m}$ of the focal subgroup, we

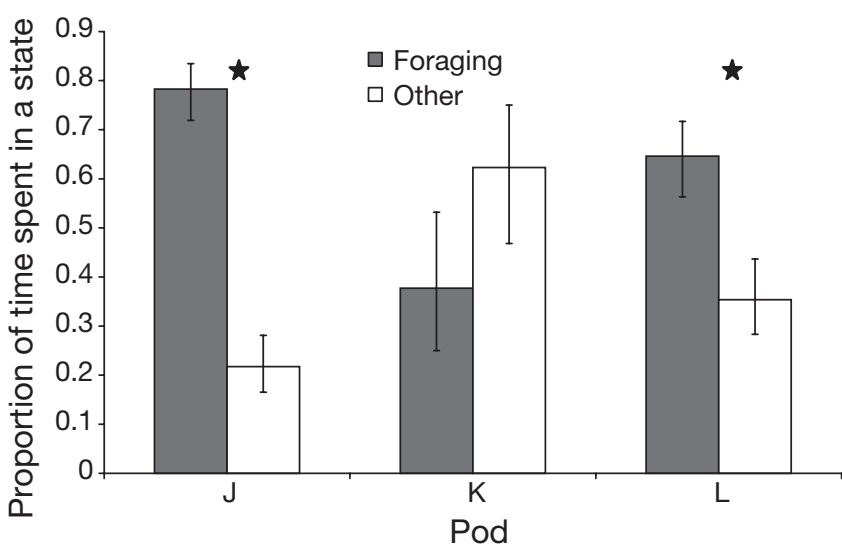

Fig. 2. Orcinus orca. Proportion of time focal killer whales spent in each activity state (their activity budget) depending on the pod membership of the focal school. Data from both sites are combined. Error bars are 95\% confidence intervals. Black stars indicate differences that are significant at the 0.05 level

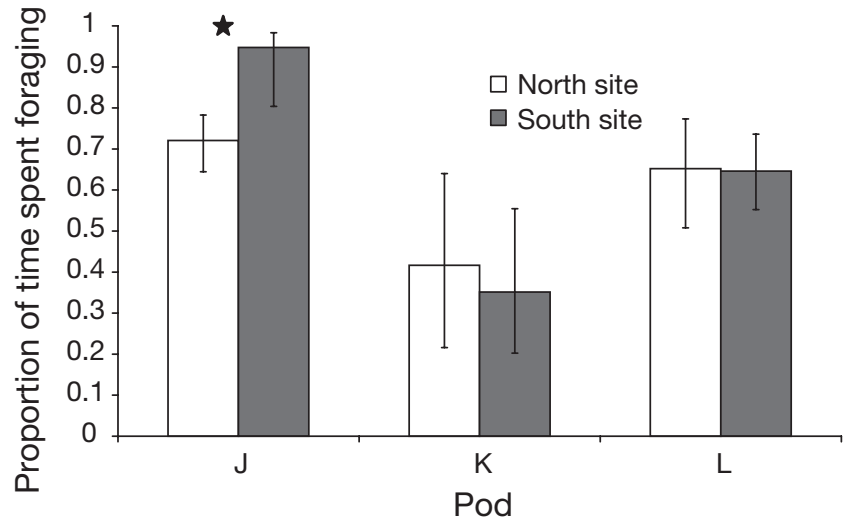

Fig. 3. Orcinus orca. Proportion of time focal killer whales spent foraging depending on the pod membership of the focal school and the site at which they were observed. Error bars are $95 \%$ confidence intervals. Black star indicates difference that is significant at the 0.05 level

wanted to assess whether more distant boats also influenced the activity states of the whales. Control samples are more difficult to obtain when considering boat presence at distances of 400 and $1000 \mathrm{~m}$, because boat traffic around the 2 sampling sites is consistently high. For this reason the current samples available did not allow us to assess the site effect in relation to boat presence within $400 \mathrm{~m}$ of the whales. Similarly, we could not assess the effects of boats within $1000 \mathrm{~m}$ of the whales because of the lack of a minimum amount of control samples. Therefore, we present only the results of the log-linear analysis assessing the effects of boat presence within $400 \mathrm{~m}$ of the whales without considering the other potential effects (i.e. merging samples obtained during all years and at both sites). Given that the site effect (or potentially the pod effect) was found to affect the activity budget in previous analyses, the following results need to be interpreted with caution. As in previous models, we compared the model, obtained from log-linear analyses, containing all 2way interactions, to the fully saturated model to assess the effect of boat presence on behavioral transitions (Lusseau 2003). This comparison, based on the difference in maximum-likelihood estimates of both models using $G^{2}$ statistics, did not reveal an effect of boat presence within $400 \mathrm{~m}$ on behavioral transitions $\left(\Delta G^{2}=\right.$ 11.0, $\Delta \mathrm{df}=9, \mathrm{p}=0.28$ ).

We then assessed the effect of boat presence within 100,400 , and $1000 \mathrm{~m}$ on the probability to continue foraging when foraging. The effect size of boat presence, i.e. the difference in the likelihood to continue foraging when foraging between control and impact situation (vessels present within the specified distance), decreased with the distance between whales and boats increasing (Fig. 4a). The effect of boat presence appeared to be only significant when boats were 
within 100 and $400 \mathrm{~m}$ (Fig. 4a, note the star and the confidence intervals), yet sample size might have prevented the detection of smaller effect size for the other treatment (1000 mi Fig. 4a). In addition, the likelihood to continue foraging when foraging increased as the distance between the focal group and boats present in the study area increased, but not significantly (Fig. 4b).
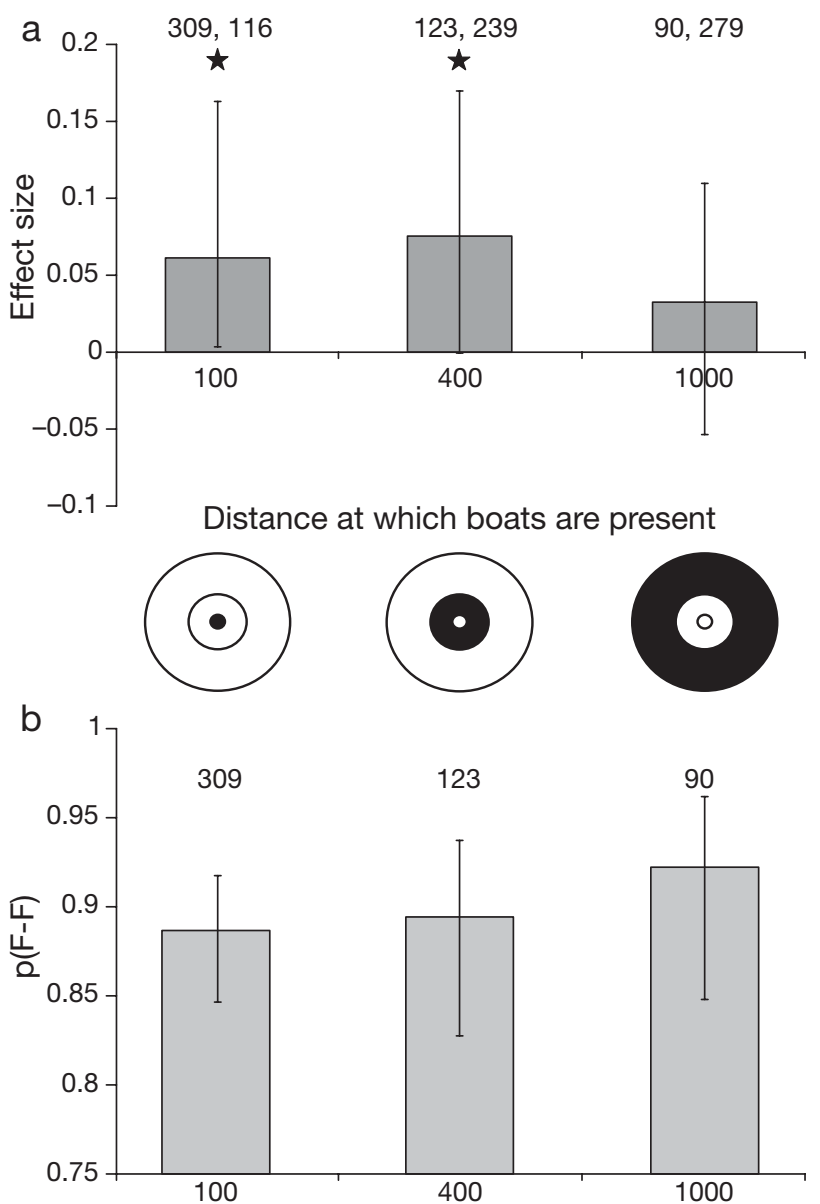

Radius of area around focal whales without boats
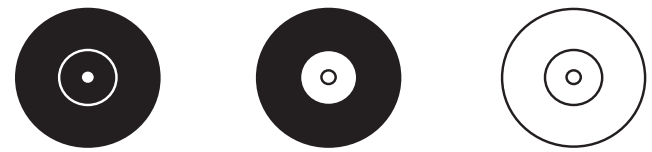

Fig. 4. Orcinus orca. Difference in the likelihood to continue foraging when foraging $\left(p_{\mathrm{F} \rightarrow \mathrm{F}}\right)$ between control and impact situations $\left(p_{\text {control }}-p_{\text {impact }}\right)$, i.e. effect size: (a) depending whether some boats were present within 100,400 , or $1000 \mathrm{~m}$ of the focal whales and (b) when there is no boat present within 100, 400 , or $1000 \mathrm{~m}$ of the focal school. The diagrams describe these 3 treatments: the focal group is at the center of the concentric doughnuts $(100,400$, and $1000 \mathrm{~m}$ radii) and boat exposure is represented in black. In order to test the effect of distance to boats, this analysis only takes into consideration samples when boats were present at the given distance. Error bars are 95\% confidence intervals for the difference. If the interval includes 0 , the difference is not significant at $p<0.05$ (indicated by a star). The number of transitions observed is given above each bar $\left(n_{\text {control }}, n_{\text {impact }}\right)$

\section{Behavioral budget variations}

We calculated the activity budgets of the whales at both sites, as well as in the presence and absence of boats. Whales tended to spend significantly more time traveling and less time foraging when boats were present within $100 \mathrm{~m}$ than when they were absent within $100 \mathrm{~m}$ (all data pooled with site effect ignored; Fig. 5a). The difference in activity budgets between both sites only involved socializing (all data pooled with boat effect ignored; Fig. 5b). Whales spent significantly more time socializing at the north site. While boat effect was not significant at $400 \mathrm{~m}$, trends in behavioral budgets depending on boat presence within $400 \mathrm{~m}$ were in the same direction as those when boats were within $100 \mathrm{~m}$ (Figs. 5a \& 6), with whales spending significantly more time traveling and significantly less time foraging.

\section{DISCUSSION}

Behavioral sequences of Orcinus orca varied significantly between locations, as expected. They also differed significantly with the presence of vessels. It is

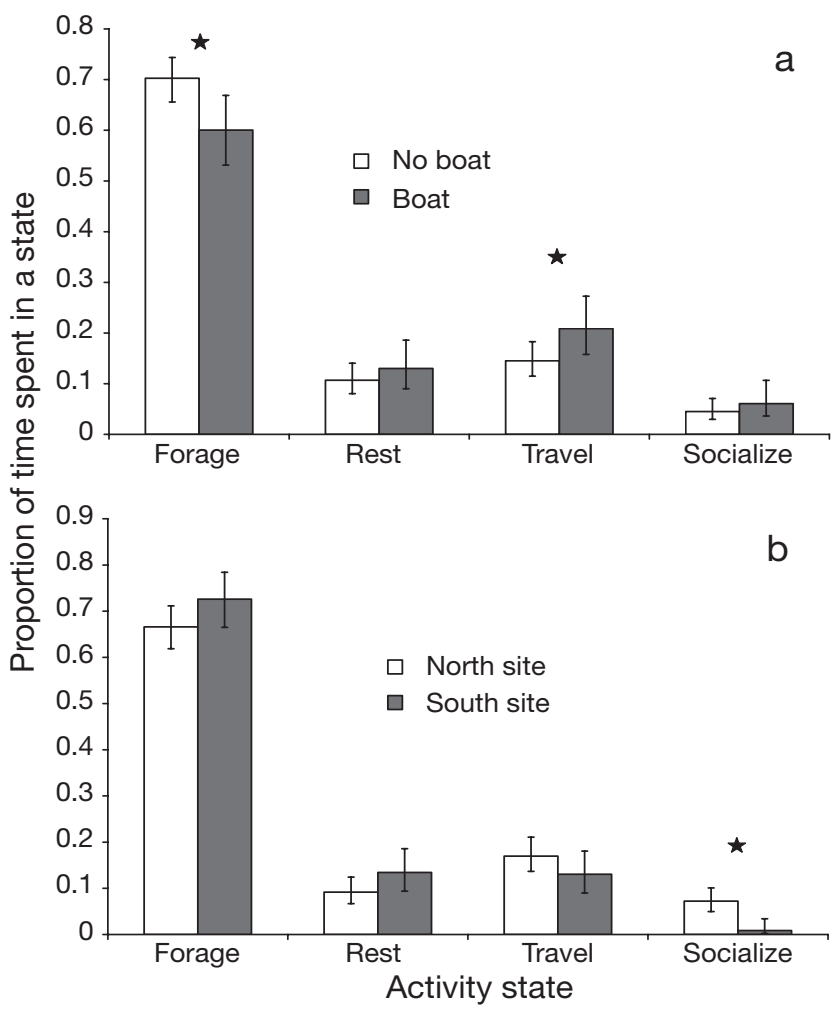

Fig. 5. Orcinus orca. Proportion of time focal killer whales spent in each activity state (their activity budget) depending on (a) the presence of boats within $100 \mathrm{~m}$ of them and (b) the site sampled. Data from all 3 pods at both study sites are combined. Error bars are $95 \%$ confidence intervals. Black stars indicate differences that are significant at the 0.05 level 


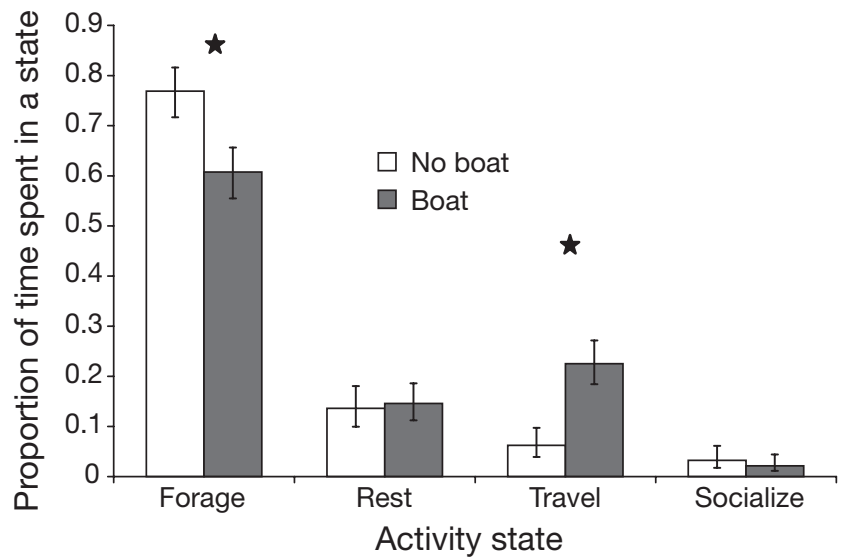

Fig. 6. Orcinus orca. Proportion of time focal killer whales spent in each activity state (their activity budget) depending on the presence of boats within $400 \mathrm{~m}$ of them, pooling across years and sites. Error bars are 95\% confidence intervals. Black stars indicate differences that are significant at the 0.05 level

possible that the observed difference between locations is actually related to pods using the 2 sites with different intensity and some differences in behavioral sequences existing between pods. J pod was more likely to be observed at the north site, while L pod was more likely to be at the south site. Similarly, schools composed of members of all 3 pods were more likely to be observed at the north site. However, boats operating close to whales (within $100 \mathrm{~m}$ ) also affected their activity budget in a similar fashion at both sites. Whales were significantly less likely to be foraging and significantly more likely to be traveling when boats were around. This finding is in agreement with previous studies of the northern resident killer whale population (Williams et al. 2006). This effect raises concerns about the implications of this short-term displacement for the ability of individuals to acquire prey and the potential for long-term repercussions at the population level, especially in the light of the level of whalewatching activities carried out with southern resident whales. Vessel activity is also believed to reduce foraging success in other species (Tursiops; Allen \& Read 2000). After controlling for effects of site and boats, there was no significant difference in the data between years. Additional years of study will be needed to determine whether the 3 different years happened to be similar in factors that vary on an annual time scale (e.g. prey abundance), or if our results will be robust across a range of conditions. The present study shows that whales are displaced short distances by the presence of vessels. Thus, whales may be displaced from optimal foraging routes. Further, Bain \& Dahlheim (1994) suggested noise would mask echolocation signals and reduce foraging efficiency. These data are also consistent with observations of northern resident whales (Williams et al. 2006). Thus, we would encourage further study to determine how noise and proximity interact to reduce foraging effort.

\section{Influence of pod identity}

Boat interactions appear to have the same effect on all 3 pods, yet more sampling is required to fully understand the interaction between the composition of focal groups and the influence of boats on their activity state. Since pods appear to use certain areas preferentially (Hauser et al. 2006), and whales use both study sites differently, it was not surprising to see that the site effect observed earlier may actually relate to a pod effect. J pod, which spends the most time in Puget Sound, was more likely to be observed foraging than the 2 other pods. That pod was also significantly more likely to be foraging at the south site than at the north site, while the 2 other pods foraged similarly at both sites.

\section{Influence of distance between focal school and boats}

Boats within $100 \mathrm{~m}$ clearly have a significant effect on whale behavior. Boats between 100 and $400 \mathrm{~m}$ also have a significant effect, although we cannot say whether boats throughout this range cause effects, or the significance is due to the effects of vessels just over $100 \mathrm{~m}$ away. More spatial resolution in the data collection protocol would have been needed to address this issue. Similar but smaller differences were observed when the closest vessels were between 400 and $1000 \mathrm{~m}$ away. However, a larger sample would be needed to determine whether effects extend beyond $400 \mathrm{~m}$. These results suggest the zone of influence of vessels in this area exceeds the $100 \mathrm{~m}$ radius in current guidelines, and that more extensive guidelines such as those developed by the Whale Watch Operators Association Northwest (2003), or those proposed by Orca Relief Citizens Alliance (2005) will be necessary to completely prevent behavioral changes caused by vessels, and more data will be needed to determine appropriate guidelines.

One potential explanation for these results is that noise impairs the ability to forage using echolocation (Aguilar Soto et al. 2006). Although Bain (2002) and Au et al. (2004) suggested whales would be able to detect prey directly in their path despite vessel noise, their ability to detect prey off to the side of their path would be impaired, as the active acoustic foraging range would be reduced by masking vessel noise (Bain \& Dahlheim 1994, Erbe 2002). Since received noise levels typically decline with distance, the closer the boats are, the more the echolocation range is reduced (Bain 2002, 
Williams et al. 2002a), potentially leading to foraging disruption, as suspected here. To test this hypothesis, acoustic monitoring would be required, as noise produced varies with engine type and the speed at which boats operate. These data were beyond the scope of the present study.

\section{CONCLUSIONS}

In this study, we found evidence consistent with changes in behavior in the presence of vessels. These effects support the development and enforcement of regulations for whale watchers, both recreational and commercial. Future research could address whether different approaches to whale watching have different degrees of impact (as paralleling and leap-frogging were compared by Williams et al. 2002a,b), and whether changes in behavior are more pronounced in some parts of the range than in others. However, since it has proven difficult to demonstrate significant differences in behavioral responses to currently accepted practices, it could be expected to take carefully controlled experiments or many years of observation to compare the implications of proposed guidelines to current guidelines. Future research could also attempt further elucidation of age, sex, pod, and individual differences in responses to vessels. Strong behavioral responses of animals to disturbance do not always indicate population-level effects. Indeed, inter-specific variability in site fidelity and availability of alternative suitable habitat make it difficult to infer populationlevel consequences from inter-specific variability in sensitivity to disturbance (Gill et al. 2001). Thus, it will be important to develop the link between short-term behavioral effects and population dynamics (see Bain 2002).

The present study echoes findings with northern resident killer whales: the presence of vessels inhibits the foraging behavior of fish-eating killer whales. This may lead to a reduction in energy acquisition, and a priority field research area would be to address whether prey capture actually is affected by vessel presence. In addition, modeling exercises should be carried out to identify potential mechanisms and the biological significance of any effects found.

Acknowledgements. We thank B. Gleason of San Juan Island National Historic Park for permission to use the south site (Permits SAJH-2004-SCI-0003 and SAJH-2005-SCI-0003), and the Reiss family for permission to use the north site. We thank E. Ashe, A. Coleman, B. Cuddihy, A. Foote, M. Foss, J. Hogan, A. Miller, F. Robertson, D. Ross, and R. Taylor for assistance with data collection. The Whale Museum's Soundwatch Program, the Marine Mammal Monitoring Program
(M3), and The Whale Watch Operators Association Northwest assisted with increasing the quantity of no-boat data at our north site. We give special thanks to D. Noren for her help with the design of this project and review of an earlier draft of the manuscript. We also thank Jason Matthiopoulos for useful comments on the manuscript. The data used in this report were funded under NMFS Contracts AB133F03SE0959, AB133F04CN0040 and AB133F05SE3965.

\section{LITERATURE CITED}

Aguilar Soto NA, Johnson M, Madsen PT, Tyack PL, Bocconcelli A, Borsani JF (2006) Does intense ship noise disrupt foraging in deep-diving Cuvier's beaked whales (Ziphius cavirostris)? Mar Mamm Sci 22:690-699

Allen MC, Read AJ (2000) Habitat selection of foraging bottlenose dolphins in relation to boat density near Clearwater, Florida. Mar Mamm Sci 16:815-824

Au WWL, Ford JKB, Horne JK, Newman Allman KA (2004) Echolocation signals of free-ranging killer whales (Orcinus orca) and modeling of foraging for chinook salmon (Oncorhynchus tshawytscha). J Acoust Soc Am 115: 901-909

Bain DE (2002) A model linking energetic effects of whale watching to killer whale (Orcinus orca) population dynamics. Orca Relief Citizens Alliance, Friday Harbor, WA. Available at: http://orcarelief.org/docs/bain_paper. pdf

Bain DE, Dahlheim ME (1994) Effects of masking noise on detection thresholds of killer whales. In: Loughlin TR (ed) Marine mammals and the 'Exxon Valdez'. Academic Press, San Diego, CA, p 243-256

Bejder L, Samuels A, Whitehead H, Gales N (2006) Decline in relative abundance of bottlenose dolphins exposed to long-term disturbance. Conserv Biol 20(6):1791-1798

Bigg MA, Olesiuk PF, Ellis GM, Ford JKB, Balcomb KC III (1990) Social organization and genealogy of resident killer whales (Orcinus orca) in the coastal waters of British Columbia and Washington State. Rep Int Whaling Comm 12(Spec Issue):383-405

Cane VR (1959) Behaviour sequences as semi-Markov chains. J R Stat Soc Ser B Methodological 21:36-58

Caswell H (2001) Matrix population models. Sinauer Associates, Boston, MA

Connor RC, Wells RS, Mann J, Read AJ (2000) The bottlenose dolphin. In: Mann J, Connor RC, Tyack PL, Whitehead H (eds) Cetacean societies. University of Chicago Press, London, $\mathrm{p}$ 91-125

Erbe C (2002) Underwater noise of whale-watching boats and potential effects on killer whales (Orcinus orca), based on an acoustic impact model. Mar Mamm Sci 18:394-418

Felleman FL, Heimlich-Boran JR, Osborne RW (1991) Feeding ecology of the killer whale (Orcinus orca). In: Pryor KW, Norris KS (eds) Dolphin societies: discoveries and puzzles. University of California Press, Berkeley, CA, p 113-147

Ford JKB, Ellis GM, Balcomb KC (2000) Killer whales: the natural history and genealogy of Orcinus orca in British Columbia and Washington, 2nd edn. University of British Columbia Press, Vancouver, BC

Galicia E, Baldassare GA (1997) Effects of motorized tourboats on the behavior of non-breeding American flamingos in Yucatan, Mexico. Conserv Biol 11:1159-1165

Gill JA, Norris K, Sutherland WJ (2001) Why behavioural responses may not reflect the population consequences of human disturbance. Biol Conserv 97:265-268 
Guttorp P (1995) Stochastic modeling of scientific data. Chapman and Hall, London

Hauser DDW, VanBlaricom GR, Holmes EE, Osborne RW (2006) Evaluating the use of whalewatch data in determining killer whale (Orcinus orca) distribution patterns. J Cet Res Manag 8:273-281

Heimlich-Boran JR (1988) Behavioral ecology of killer whales (Orcinus orca) in the Pacific Northwest. Can J Zool 66: 565-578

Hoelzel AR (1993) Foraging behaviour and social group dynamics in Puget-Sound killer whales. Anim Behav 45: 581-591

Killer Whale Recovery Team (2005) Recovery strategy for the northern and southern resident killer whales (Orcinus orca) in Canada. Species at Risk Recovery Strategy Series, Fisheries and Oceans Canada, Ottawa

Krahn MM, Ford MJ, Perrin WF, Wade PR and others (2004) 2004 Status review of southern resident killer whales (Orcinus orca) under the Endangered Species Act. NOAA Tech Memo NMFSNWFSC-62, US Department of Commerce, Washington, DC

Lacy KE, Martins EP (2003) The effect of anthropogenic habitat usage on the social behavior of a vulnerable species, Cyclura nubila. Anim Conserv 6:3-9

Lusseau D (2003) The effects of tour boats on the behavior of bottlenose dolphins: using Markov chains to model anthropogenic impacts. Conserv Biol 17:1785-1793

Lusseau D (2004) The hidden cost of tourism: effects of interactions with tour boats on the behavioural budget of two populations of bottlenose dolphins in Fiordland, New Zealand. Ecol Soc 9: art. 2

Lusseau D (2005) The residency pattern of bottlenose dolphins Tursiops sp. in Milford Sound, New Zealand, is related to boat traffic. Mar Ecol Prog Ser 295:265-272

Lusseau D, Lusseau SM, Bejder L, Williams R (2006) An individual-based model to infer the impact of whalewatching on cetacean population dynamics. IWC SC/58/WW7 Report to the 58th meeting of the International Whaling Commission Scientific Committee, St. Kitts and Nevis

Olesiuk PF, Bigg MA, Ellis GM (1990) Life history and population dynamics of resident killer whales (Orcinus orca) in the coastal waters of British Columbia and

Editorial responsibility: Jason Matthiopoulos, St. Andrews, UK
Washington State. Rep Int Whaling Comm 12(Spec Issue):209-243

Orca Relief Citizens Alliance (2005) The best view of our whales is from shore. Orca Relief Citizens Alliance, Friday Harbor, WA

Osborne RW (1999) A historical ecology of Salish Sea 'resident' killer whales (Orcinus orca): with implications for management. PhD dissertation, University of Victoria, Victoria, BC

Protected Resources Division (2004) Initial assessment of NOAA fisheries' critical habitat analytical review teams for 13 evolutionarily significant units of Pacific salmon and O. mykiss. NOAA Fisheries Protected Resources Division, Portland, OR

Romano TA, Keogh MJ, Kelly C, Feng P and others (2004) Anthropogenic sound and marine mammal health: measures of the nervous and immune systems before and after intense sound exposure. Can J Fish Aquat Sci 61: 1124-1134

Safina C, Burger J (1983) Effects of human disturbance on reproductive success in the black skimmer. Condor 85: 164-171

Whale Watch Operators Association Northwest (2003) Best practices guidelines-2003. Available at: www. nwwhalewatchers.org/guidelines.html

Wiles GJ (2004) Washington State status report for the killer whale. Washington Department Fish and Wildlife, Olympia, WA

Williams R, Bain DE, Ford JKB, Trites AW (2002a) Behavioural responses of male killer whales to a 'leapfrogging' vessel. J Cet Res Manag 4:305-310

Williams R, Trites A, Bain DE (2002b) Behavioural responses of killer whales (Orcinus orca) to whale-watching boats: opportunistic observations and experimental approaches. J Zool 256:255-270

Williams R, Lusseau D, Hammond PS (2006) Estimating relative energetic costs of human disturbance to killer whales (Orcinus orca). Biol Conserv 133:301-311

Williams R, Bain DE, Smith JC, Lusseau D (2009) Effects of vessels on behavior patterns of individual southern resident killer whales Orcinus orca. Endang Species Res. 6: 199-209

Submitted: July 19, 2007; Accepted: September, 25, 2008 Proofs received from author(s): December 9, 2008 